\title{
Chordoma in Nasopharynx in a 70-Year-0ld Female: A Rare Occurence
}

\author{
Bhaskar Mitra*, Subhalakshmi Sengupta, Anshita Rai, Jay Mehta, Aruna Rai Quader, \\ Subhendu Roy, Anita Borges
}

Drs. Tribedi \& Roy Diagnostic Laboratory, Kolkata, India

Email: ${ }^{\text {bhaskarmitra12@gmail.com }}$

Received 28 August 2014; revised 24 September 2014; accepted 23 October 2014

Copyright (C) 2014 by authors and Scientific Research Publishing Inc.

This work is licensed under the Creative Commons Attribution International License (CC BY). http://creativecommons.org/licenses/by/4.0/

c) (i) Open Access

\begin{abstract}
The nasopharynx is an unusual site for extraosseous chordoma. The characteristic histology and immunohistochemistry confirmed the diagnosis. The behaviour of this tumour is locally aggressive. We report a case of nasopharyngeal chordoma in an elderly patient with literature review.
\end{abstract}

\section{Keywords}

\section{Chordoma, Nasopharyngeal Tumours, Notochord}

\section{Introduction}

Chordomas are rare, locally aggressive tumours that probably originate from embryonic remnants of the notochord. The sacrum is the commonest site followed by the base of the skull/clival region. Spheno-occipital chordomas giving rise to the formation of a nasopharyngeal mass have been described in literature [1]-[3]. When skull base chordomas occur at an extraosseous location (without lytic bone destruction), they may mimic other lesions of the nasopharynx.

It is important to consider extraosseous chordoma in the differential diagnosis of tumors in the nasopharynx because it requires a very different treatment plan and carries its own unique prognosis. We like to share our experience of a primary extraosseous chordoma involving the nasopharynx.

\section{Case Report}

A 70-year-old female, presented with persistent and profuse anterior rhinorrhea, for more than one year. The discharge was bilateral, had a bad odour and was associated with mild subjective hearing loss, nasal respiratory

\footnotetext{
"Corresponding author.
}

How to cite this paper: Mitra, B., Sengupta, S., Rai, A., Mehta, J., Quader, A.R., Roy, S. and Borges, A. (2014) Chordoma in Nasopharynx in a 70-Year-Old Female: A Rare Occurence. International Journal of Otolaryngology and Head \& Neck Surgery, 3, 342-346. http://dx.doi.org/10.4236/ijohns.2014.36061 
failure and closed rhinolalia.

Exploration by oropharyngoscopy revealed a mucosa covered soft mass, measuring $2.5 \times 2 \mathrm{cms}$ protruding from the soft palate into the central region of the posterior nasopharyngeal wall. The tumour was not indurated and showed no fluctuation or inflammatory signs. Otoscopy revealed bilateral seromucinous otitis.

A head and neck CT scan showed an ill defined heterogeneously enhancing soft tissue attenuating polypoid mass within the nasopharyngeal cavity (Figure 1). In the posterior aspect of the mass evidence of porous erosion is seen in anterior margin of the basi-sphenoid. The mass has occluded the posterior nasal air spaces and nasopharynx. The soft palate is thickened and inseparable from the mass superiorly. The pterygoid muscles and adjacent fat planes are maintained. No intrasphenoid or intracerebral extension of the mass was seen. The paranasal sinuses are well aerated and clear. Other routine investigations are within normal limits.

Pharyngoscopic excision biopsy was performed. On gross examination the lesion appeared soft, polypoid, multilobulated, semi translucent and grayish. Whole of it was processed. Microscopically it shows a tumour composed of nests of cells tending to be arranged in cords set in a pale matrix of mucopolysaccharide with a characteristic physaliphorous appearance (Figures 2(A)-(C)). Areas of necrosis not seen. The tumour cells do not show significant mitotic activity or nuclear anaplasia. Areas of congestion and hemorrhage are present. The overlying respiratory epithelium was unremarkable (Figure 2(A)). From the Haematoxyline and Eosin stained slides a provisional diagnosis of Chordoma was made. Immunohistochemistry was performed; the tumour cells were immunopositive for Cytokeratin, EMA [epithelial membrane antigen] and S-100 (Figure 3), confirming the diagnosis of nasopharyngeal chordoma.

Surgical excision of the lesion was performed through skull base approach. Imaging study helped to rule out any residual tumour by assessing the extent of tumour. Postoperative course being uneventful, the patient was discharged after 10 days and was monitored on an outpatient basis. The patient remains asymptomatic and without any abnormal findings reported on control imaging studies till date.
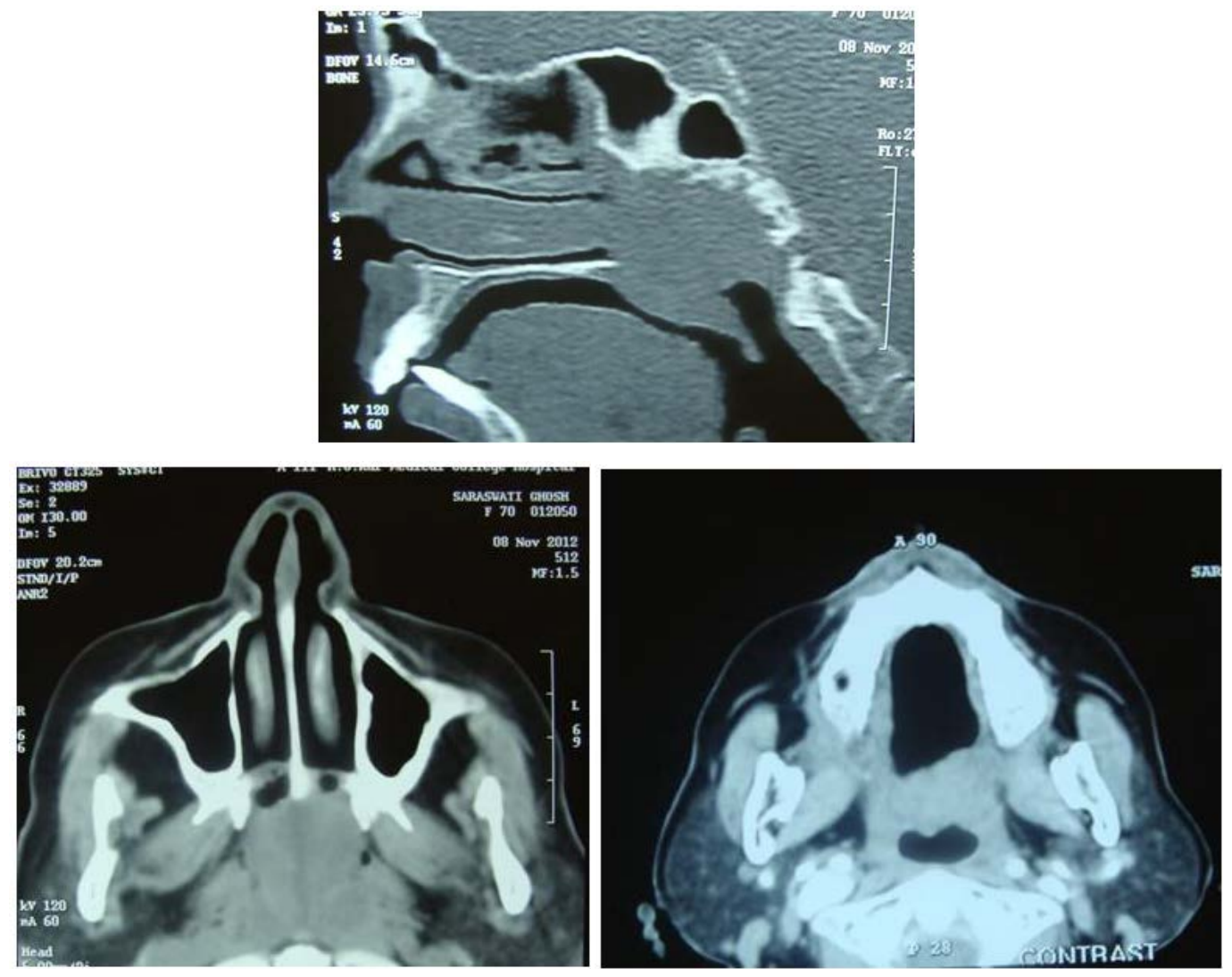

Figure 1. Coronal and sagital section CT scan showed (plain and contrast-enhanced) heterogeneouslyenhancing soft tissue lobulated mass in the nasopharynx with evidence of bone erosion at the roof of nasopharynx (clival base). 


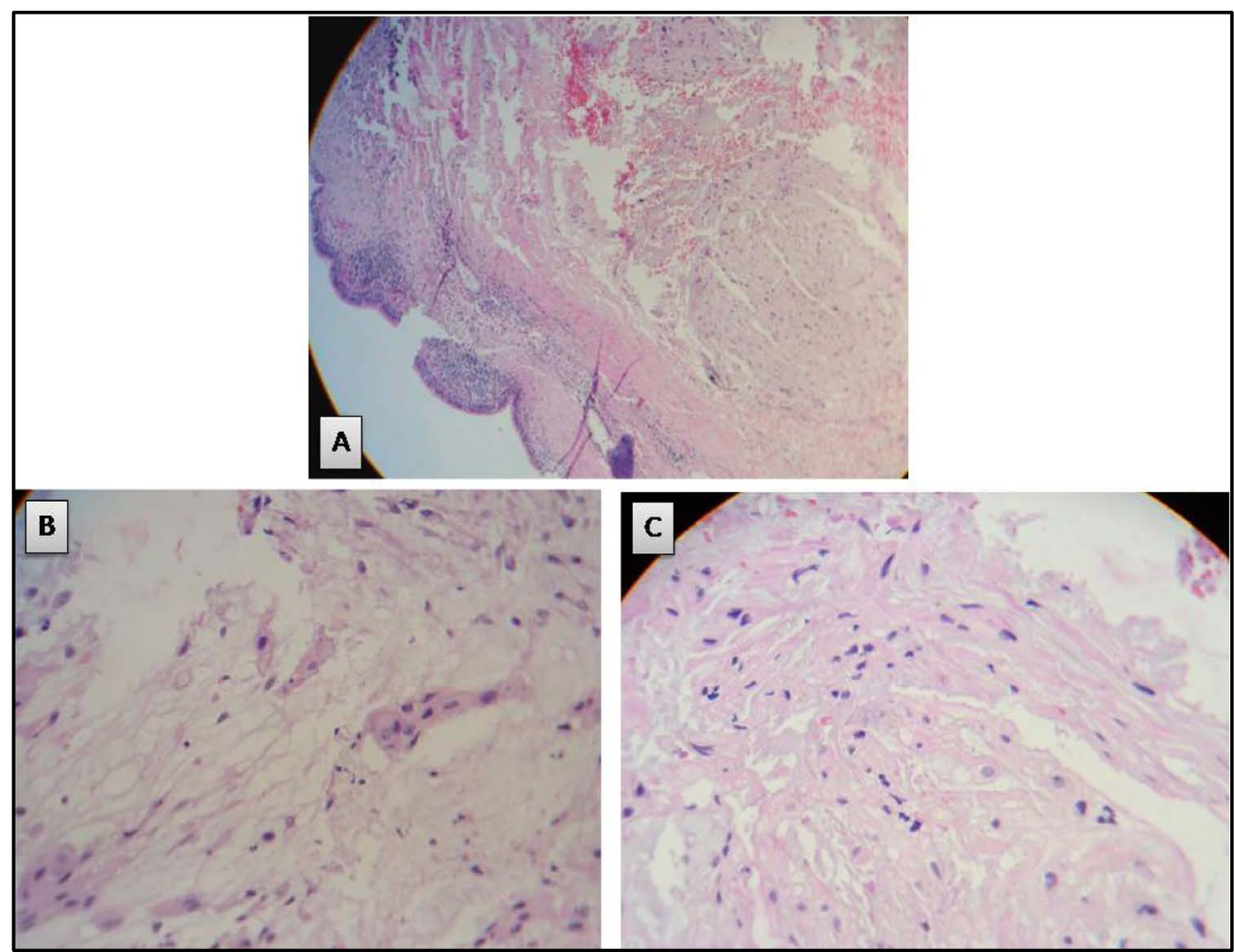

Figure 2. Tumour with overlying respiratory epithelium [(A), 10× H\&E stain]. Nests of tumour cells tending to be arranged in cords set in a pale matrix of mucopolysaccharide with a characteristic physaliphorous appearance [(B) \& (C), 40× H\&E stain].

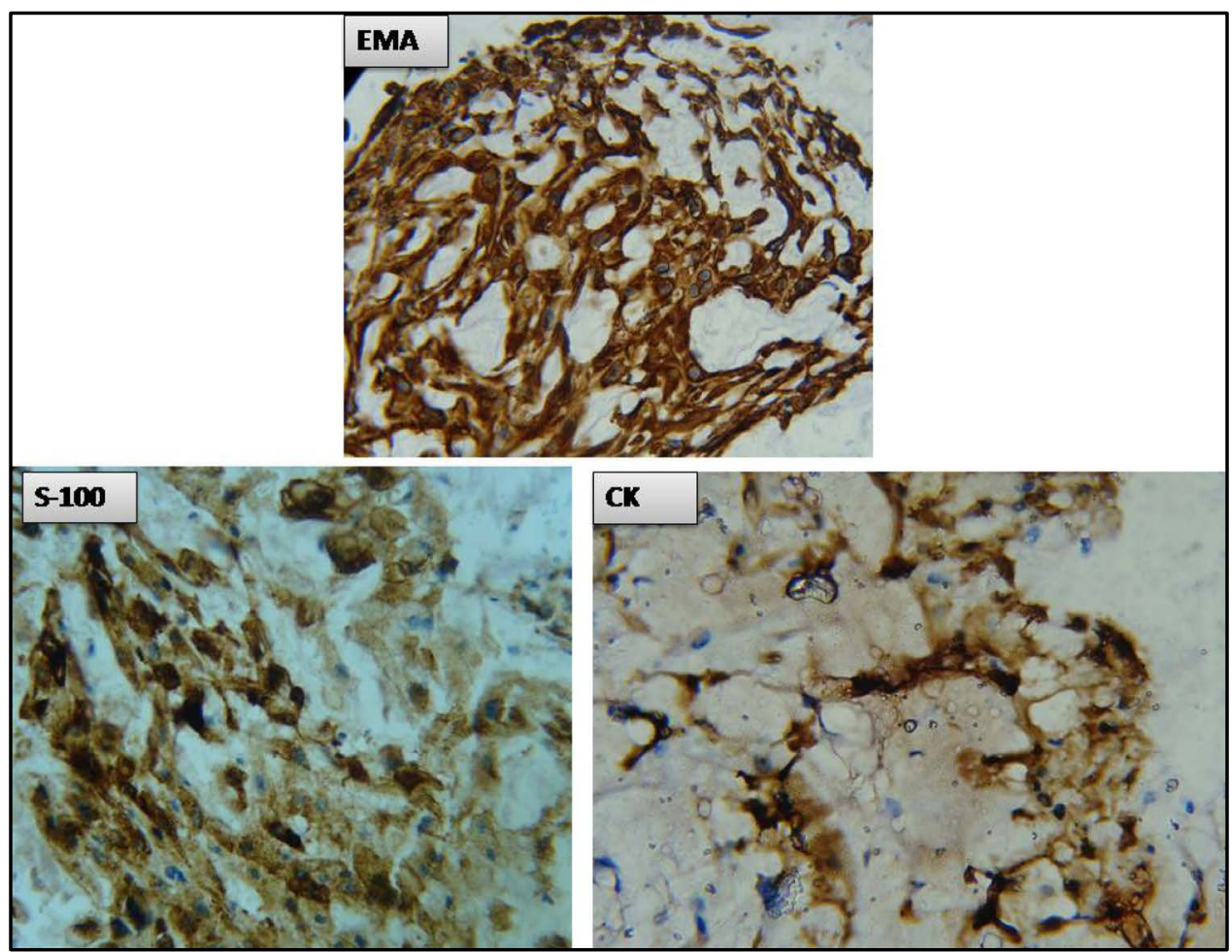

Figure 3. The tumour cells are immunopositive for Cytokeratin, EMA [epithelial membrane antigen] and S-100. 


\section{Discussion}

Extraosseous nasopharyngeal chordoma is primarily a lesion of the nasopharyngeal soft tissues. Nasopharynx is an unusual site for chordoma. The histological features of this tumour were unlike that of a nasopharyngeal carcinoma or a lymphoma [4]-[6]. A small extraosseous chordoma may mimic a Tornwaldt cyst, a benign notochordal remnant entity.

Chordomas account for $1 \%$ of intracranial tumors and $4 \%$ of all primary bone tumors [7]-[10]. They may occur at any age but are usually seen in adults, with a peak prevalence in the 4th decade of life, but the age of our patient (seventh decade) is unusual. Chordomas have a 2:1 male predilection and affect whites more than blacks [11]-[13]. Intracranial chordomas constitute one-third of all chordomas and usually occur in the vicinity of the clivus, often in the region of the spheno-occipital synchondrosis [8] [9]. Although intracranial chordomas are generally slow growing, their intimate relation to critical structures and extremely high local recurrence rate have often resulted in high mortality rates in the past. However, recent advances in skull base surgery and radiation therapy now provide the opportunity for cure [14] [15].

Generally, chordomas grow slowly and produce symptoms insidiously. Symptoms of intracranial chordomas vary with the location and proximity of the lesion to critical structures and the sites of extension. The most common initial complaint is diplopia related to cranial nerve palsy and headache. Among cranial nerves, the abducent nerve is the most commonly affected [13]. Due to the extraosseous location of these lesions, the typical lytic changes in the clivus are absent; thus, the initial diagnosis is difficult. Intracranial extensions are also not found, though some amount of bone erosion is evident in the CT scan. The aggressive features of chordomas as evident in literature are lytic changes in the osseous structures, such as destruction of the superficial surface of the clivus and bones of the posterior sinonasal region, which are absent in our case. Our patient had a nasopharyngeal lesion with mass effect without any typical neurologic symptoms and cranial neuropathies as commonly seen in chordomas. Chordomas are thought to arise from physaliphorous cells as described by Virchow [16]. The notochord is a primitive cell line around which the skull base and axial skeleton develop. The major postoperative problem is tumor recurrence as a consequence of incomplete excision.

Both CT and MR imaging are used in the evaluation of chordoma. CT is ideal for evaluating the bony involvement, whereas MR imaging is useful for evaluating the surrounding soft tissues and extension into adjacent structures. MR imaging is considered the gold standard in pretreatment and post treatment evaluation of chordomas [11]. On CT, the typical appearance of an extraosseous chordoma is a lobular hypoattenuated soft-tissue mass with areas of dystrophic calcification and lytic changes of affected osseous structures. Scattered areas of hyperattenuation are consistent with descriptions in the literature of blood products and intratumoral hemorrhage in typical chordomas [11] [12].

Anterior tumor extension can involve the sphenoid sinus and, less commonly, the posterior ethmoid sinus, but extension to the paranasal sinuses is not seen in our case.

Surgical removal is a very effective treatment for intracranial chordomas. Longer survival rates have been associated with more extensive tumor removal [8]. With advances in imaging technology, presurgical evaluation can now provide more detailed knowledge of the lesion and suggest the best surgical approach. Local recurrence of intracranial chordomas is still common regardless of the mode of therapy [17].

\section{Conclusion}

Extraosseous nasopharyngeal chordomas are rare tumors with its own unique characteristics and should be considered in the differential diagnosis of nasopharyngeal lesions.

\section{Acknowledgements}

We would like to thank Dr. Ruby Sen for her kind assistance in this paper. The authors also gratefully acknowledge the assistance of the laboratory staffs of the Drs. Tribedi \& Roy Diagnostic Laboratory.

\section{Consent}

Written informed consent was obtained from the patient for publication of this case report and accompanying images. 


\section{Competing Interest}

There is no conflict of interest related to the work among the authors in this study.

\section{Authors' Contribution}

BM, SS and ARQ collected and analyzed the patient's data. SS and AR performed the gross examination.BM; ARQ \& SR performed the histological examination and prepared the manuscript. JM \& AB interpreted the Immunohistochemical slides and reviewed the case. ARQ \& SR have supervised the work and final correction of the manuscript done by them. All the authors read and approved the final manuscript.

\section{References}

[1] Firooznia, H., Pinto, R., Lin, J., et al. (1976) Chordomas: Radiologic Evaluation of 20 Cases. American Journal of Roentgenology, 127, 797-805. http://dx.doi.org/10.2214/ajr.127.5.797

[2] Omerod, R. (1960) A Case of Chordomas Presenting in the Nasopharynx. Journal of Laryngology and Otology, 74, 245-254. http://dx.doi.org/10.1017/S0022215100056528

[3] Eisemann, M.L. (1980) Sphenooccipital Chordomas Presenting as a Nasopharyngeal Mass. A Case Report. Annals of Otology, Rhinology \& Laryngology, 89, 271-275. http://dx.doi.org/10.1177/000348948008900318

[4] King, A.D., Lei, K.I., Richards, P.S., et al. (2003) Non-Hodgkin’s Lymphoma of the Nasopharynx: CT and MR Imaging. Clinical Radiology, 58, 621-625. http://dx.doi.org/10.1016/S0009-9260(03)00182-X

[5] Weber, A.L., Al-Arayedh, S. and Rashid, A. (2003) Nasopharynx: Clinical, Pathologic and Radiologic Assessment. Neuroimaging Clinics of North America, 13, 465-483. http://dx.doi.org/10.1016/S1052-5149(03)00041-8

[6] Urquhart, A. and Berg, R. (2001) Hodgkin's and Non-Hodgkin's Lymphoma of the Head and Neck. Laryngoscope, 111, 1565-1569. http://dx.doi.org/10.1097/00005537-200109000-00013

[7] Erdem, E., Angtuaco, E., Hemert, R., et al. (2003) Comprehensive Review of Intracranial Chordoma. Radiographics, 23, 995-1009. http://dx.doi.org/10.1148/rg.234025176

[8] DiFrancesco, L.M., Castillo, C.A.D. and Temple, W.J. (2006) Extra-Axial Chordoma. Archives of Pathology \& Laboratory Medicine, 130, 1871-1874.

[9] Masui, K., Kawai, S., Yonezawa, T., et al. (2006) Intradural Retroclival Chordoma without Bone Involvement. Neurologia Medico-Chirurgica (Tokyo), 46, 552-555. http://dx.doi.org/10.1002/1097-0142(195211)5:6<1170::AID-CNCR2820050613>3.0.CO;2-C

[10] Dahlin, D.C. and MacCharty, C.S. (1952) Chordoma: A Study of 59 Cases. Cancer, 5, 1170-1178. http://dx.doi.org/10.1002/1097-0142(195211)5:6<1170::AID-CNCR2820050613>3.0.CO;2-C

[11] Heffelfinger, M.J., Dahlin, D.C., MacCarty, C.S. and Beabout, J.W. (1973) Chordomas and Cartilaginous Tumors at the Skull Base. Cancer, 32, 410-420. http://dx.doi.org/10.1002/1097-0142(197308)32:2<410::AID-CNCR2820320219>3.0.CO;2-S

[12] McMaster, M.L., Goldstein, A.M., Bromley, C.M., Ishibe, N. and Parry, D.M. (2001) Chordoma: Incidence and Survival Patterns in the United States, 1973-1995. Cancer Causes Control, 12, 1-11. http://dx.doi.org/10.1023/A:1008947301735

[13] Mizerny, B.R. and Kost, K.M. (1995) Chordoma of the Cranial Base: The McGill Experience. Journal of Otolaryngology, 24, 14-19.

[14] Raffel, C., Wright, D.C., Gutin, P.H. and Wilson, C.B. (1985) Cranial Chordomas: Clinical Presentation and Results of Operative and Radiation Therapy in Twenty-Six Patients. Neurosurgery, 17, 703-710. http://dx.doi.org/10.1227/00006123-198511000-00002

[15] Al-Mefty, O. and Borba, L.A. (1997) Skull Base Chordomas: A Management Challenge. Journal of Neurosurgery, 86, 182-189. http://dx.doi.org/10.3171/jns.1997.86.2.0182

[16] Ribbert, H. and Virchow, R. (1959) Chordoma. In: Windeyer, B.W., Ed., Proceedings of the Royal Society of Medicine, 52, 1088-1100.

[17] Castro, J.R., Linstadt, D.E., Bahary, J.P., et al. (1994) Experience in Charged Particle Irradiation of Tumors of the Skull Base: 1977-1992. International Journal of Radiation Oncology, Biology, Physics, 29, 647-655. http://dx.doi.org/10.1016/0360-3016(94)90550-9 
Scientific Research Publishing (SCIRP) is one of the largest Open Access journal publishers. It is currently publishing more than 200 open access, online, peer-reviewed journals covering a wide range of academic disciplines. SCIRP serves the worldwide academic communities and contributes to the progress and application of science with its publication.

Other selected journals from SCIRP are listed as below. Submit your manuscript to us via either submit@scirp.org or Online Submission Portal.
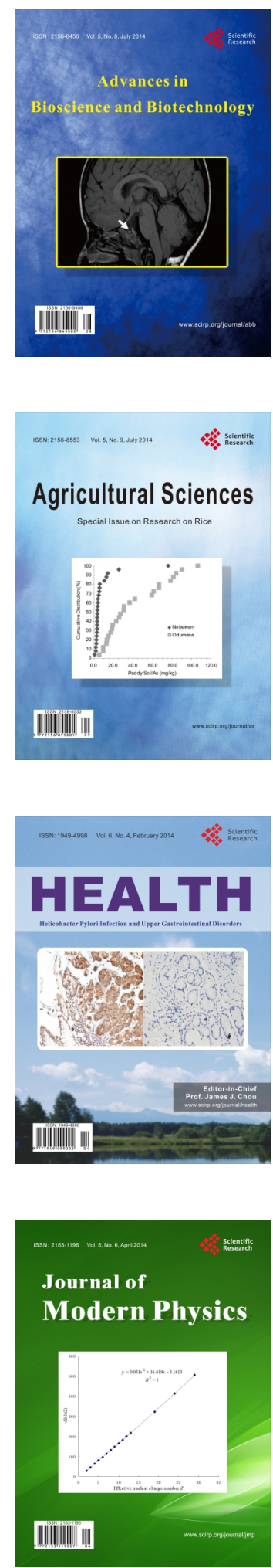
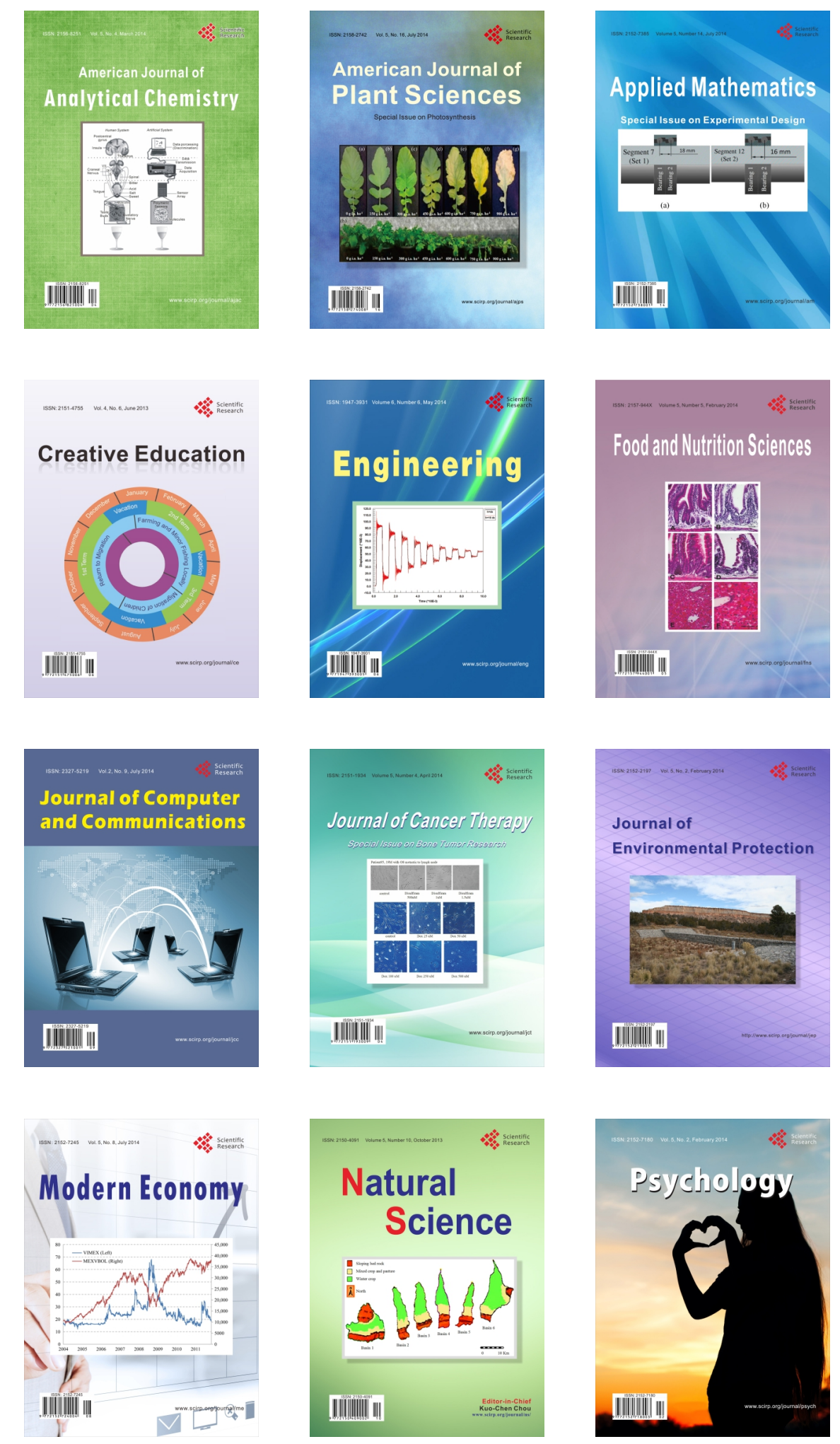